\author{
RESEARCHPAPER
}

\title{
Combined mutagenic improvement of Bacillus licheniformis SK7 for cost-effective protease production
}

\author{
SANJAY KUMAR YADAV ${ }^{1}$, POONAM SINGH ${ }^{1}$, KASHYAP KUMAR DUBEY ${ }^{2}$ AND BHANU P. SINGH ${ }^{2}$ \\ ${ }^{1}$ Department of Molecular and Cellular Engineering, Jacob School of Biotechnology and Bio-Engineering, Sam \\ Higginbottom Institute of Agriculture, Technology and Sciences, ALLAHABAD (U.P.) INDIA \\ ${ }^{2}$ Microbial Biotechnology Laboratory, University Institute of Engineering and Technology, M.D. University, ROHTAK \\ (HARYANA) INDIA \\ Email : drpoonam.singh1@gmail.com
}

Article Info :Received : 10.12.2015; Accepted : 09.02.2016

The strain improvement of developed Bacillus licheniformis SK7 was achieved with the combination of physical and chemical agents i.e., UV + NTG + EMS by gradually mutation and positive selection. In case of UV light 99 per cent killing for successful selection of mutants was $6 \mathrm{~min}$ and $10 \mathrm{~cm}$ distance from source, while in case of EMS and NTG the concentration found effective was $200 \mu \mathrm{M}, 30 \mu \mathrm{M}$, respective for $15 \mathrm{~min}$. The mutant Bacillus licheniformis SK7 SN 43 was successfully developed and found stable having higher production of protease $(662 \mathrm{U} / \mathrm{ml})$ under optimized medium and physical conditions of fermentation than the wild type Bacillus licheniformis SK7 (472 U/ml) under the same conditions of fermentation.

Key words : Mutagenesis, NTG, UV light, Strain improvement, Protease

How to cite this paper : Yadav, Sanjay Kumar, Singh, Poonam, Dubey, Kashyap Kumar and Singh, Bhanu P. (2016). Combined mutagenic improvement of Bacillus licheniformis SK7 for cost-effective protease production. Asian J. Bio. Sci., 11 (1) : 91-94 [Special Issue of AFBSAH2016]. 